\title{
Littré Strangled Umbilical Hernia: Case Report
}

\author{
Júlia Saraiva Avelino Silveira ${ }^{1}$, Jessica Andrade Freire ${ }^{1}$, \\ Gustavo Santana Garcia ${ }^{1}$, Carlos Henrique Morais Reis ${ }^{1}$, \\ Audria Taiane Souza dos Santos ${ }^{1}$, Matheus Castro de Almeida ${ }^{1}$, \\ João Henrique Godoy Rodrigues ${ }^{1}$
}

${ }^{1}$ General Surgery Resident at Faculty of Medicine of São José do Rio Preto, Hospital de Base, São José do Rio Preto, São Paulo, Brazil

\begin{abstract}
Littré hernia is considered to be an extremely rare surgical finding with few cases described in recent literature. It is characterized by the presence of Meckel's diverticulum in the interior of the hernia sac. The aim of this article is to report the case of an elderly patient intraoperatively diagnosed with Littré's strangled umbilical hernia, associated with the insertion of Treitz ligament in anomalous position.
\end{abstract}

Keywords: Littre Hernia, Meckel’s Diverticulum, Rare Hernias, Umbilical Hernia

\section{Background}

Resulting from the incomplete closure of the omphalomesenteric duct during the embryonic period, Meckel's diverticulum is deemed as the most common malformation of the gastrointestinal tract, affecting $2 \%$ of the population(6). Usually asymptomatic, it presents complications in approximately $5 \%$ of cases and might cause inflammation, obstruction, perforation and bleeding(4). The protrusion of this diverticulum caused by a defect in the abdominal wall is denominated Littré's hernia. Initially described by French doctor Alexis de Littré in 1700, Littré's hernia is an extremely rare surgical event and is usually diagnosed during the intraoperative period. The anatomical locus of the hernia might vary and is normally related to the inguinal $(50 \%)$, femoral $(20 \%)$ and inguinal $(20 \%)$ region(1). In the present article, we report the case of Littré's strangled umbilical hernia in a 63-year-old patient, treated in the emergency care unit of a tertiary hospital in the State of São Paulo.

\section{Case Report}

Male patient, 63 years old, hypertensive and previously diagnosed with umbilical hernia 2 years before, was brought into the hospital with intense pain in the umbilical region associated with an interruption of bowel movement since 12 hours before. During the physical exam he presented an umbilical hernia with traces of strangling, and was immediately sent to the operating room. During the intraoperative, in the abdominal cavity inventory, the presence of Meckel's diverticulum with signs of widespread necrosis in the interior of the umbilical hernia sac was observed, as well as the anomalous position of the angle of Treitz, which was located to the right side of the mesenteric arteries, along with numerous diverticulum in the jejunum and transverse colon. A segmental enterectomy of the affected portion was carried out, followed by a terminoterminal anastomosis. The patient was sent to the intensive care unit (ICU) in the immediate postoperative, evolving with clinical improvement and hospital discharge five days after his admission for outpatient care.

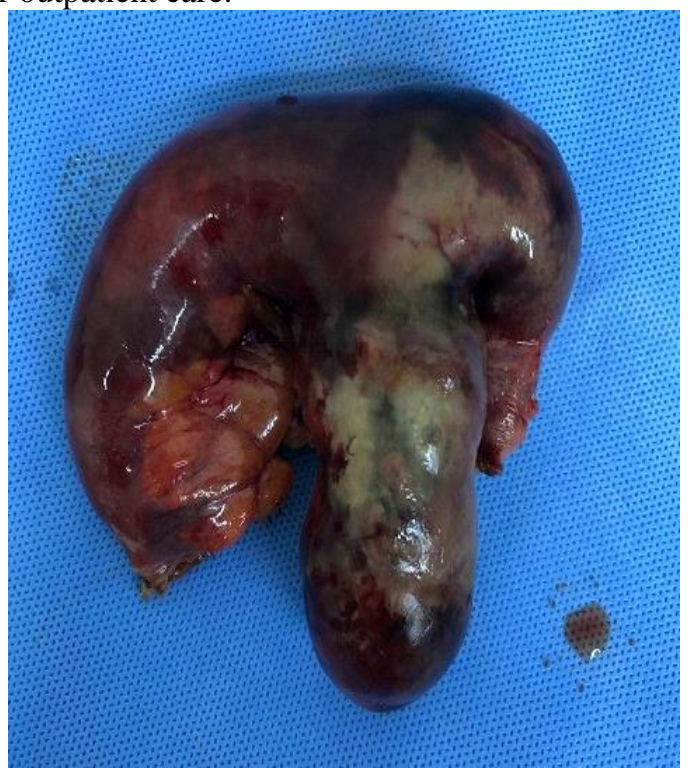

Figure 1: Necrotic Meckel's diverticulum

This article is published under the terms of the Creative Commons Attribution License 4.0 Author(s) retain the copyright of this article. Publication rights with Alkhaer Publications. Published at: http://www.ijsciences.com/pub/issue/2020-11/ DOI: 10.18483/ijSci.2416; Online ISSN: 2305-3925; Print ISSN: 2410-4477 


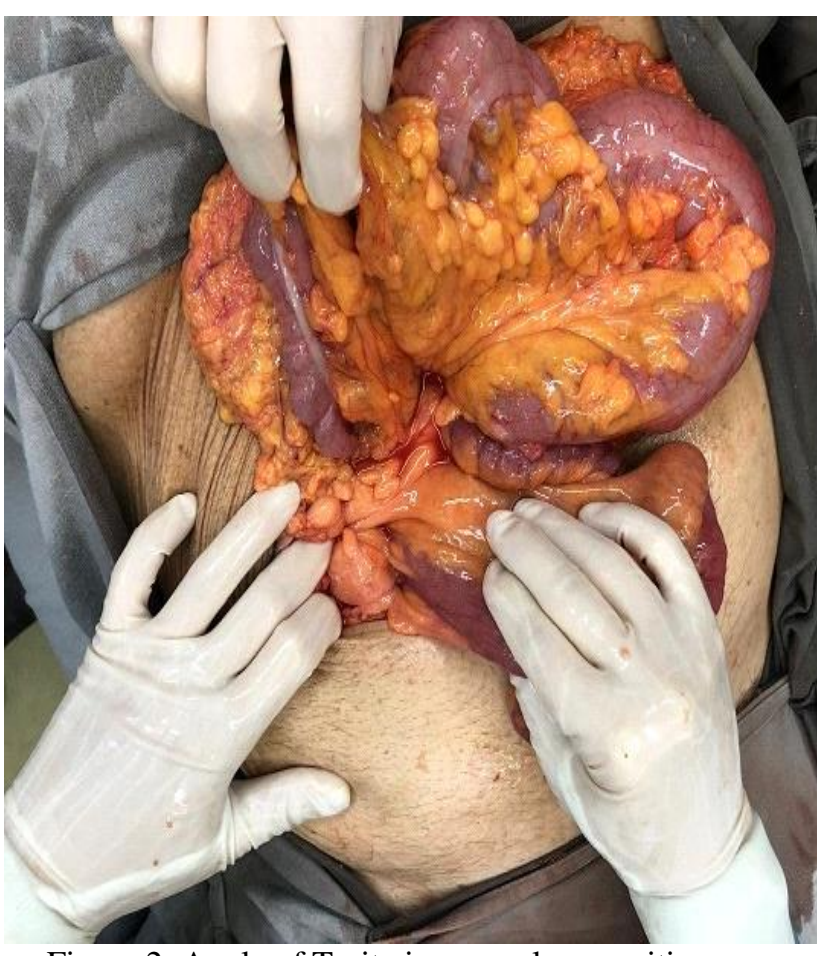

Figure 2: Angle of Treitz in anomalous position

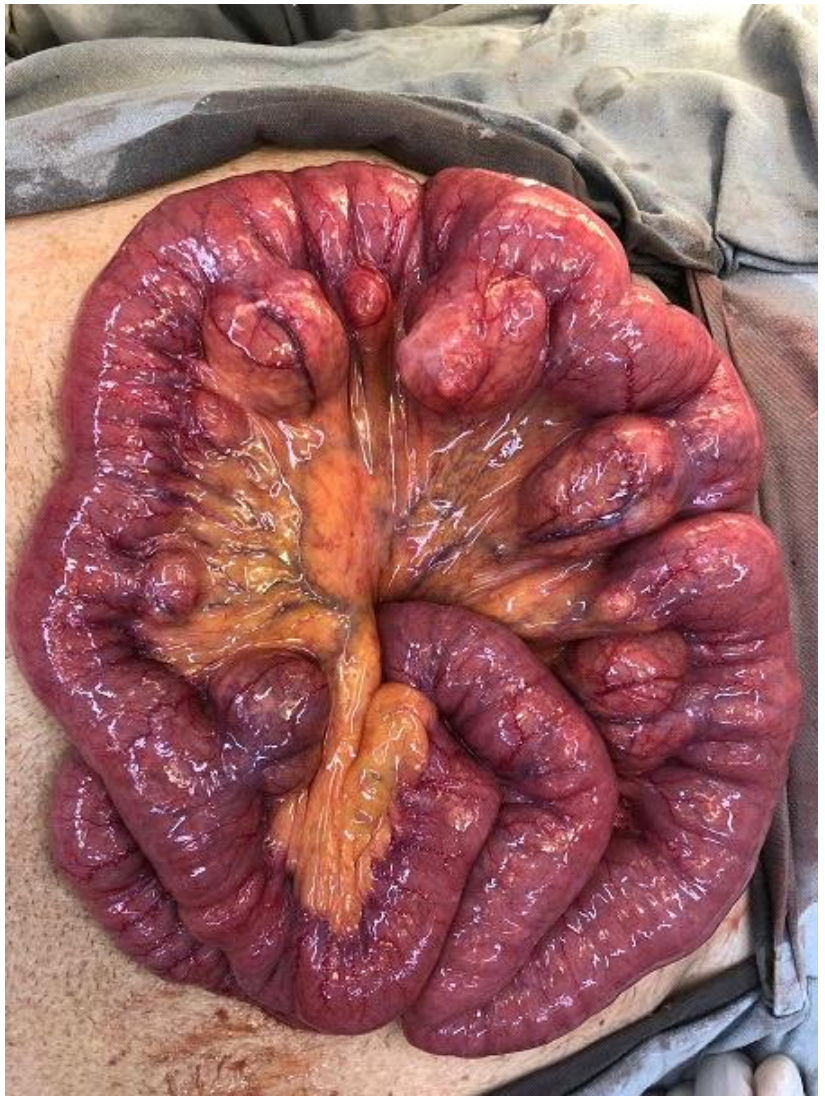

Figure 3: Diverticuli in the jejunum

\section{Discussion}

Meckel's diverticulum is a real diverticulum, located in the antimesenteric border of the ileum, approximately eighty centimeters from the ileocecal valve, and is the result of the incomplete obliteration of omphalomesenteric duct during the embryonic period(3). Initially described in 1808 by the German doctor Johann Meckel, it is considered the most common congenital anomaly of the gastrointestinal tract, affecting $2 \%$ of the population(6). Usually asymptomatic, it can cause various complications such as inflammation, obstruction, perforation and bleeding, mainly occurring before the second year of life in $60 \%$ of cases(6). The chances of complications diminish with the advancement of age.

Littré hernia corresponds to only $10 \%$ of symptomatic cases of Meckel's diverticulum(1). It is characterized by the protrusion of the diverticulum due to a defect in the abdominal wall, as initially described by the French doctor Alexis de Littré. Although being initially described as a femoral hernia, which presently corresponds to $10 \%$ of cases, it may occur in diverse topographies, such as the inguinal $(50 \%)$ and umbilical $(20 \%)$ regions, among others $(10 \%)$.

Mainly affecting the male sex, Littré hernia can be classified between two main types: true hernia, when consisting of only Meckel's diverticulum in its interior, and combined hernia, when there is a presence of other viscera in the hernia sac. In most cases, the diagnosis is given during the surgical act, since its symptoms are usually late and unspecified. The utilization of imaging methods such as the total abdomen computed radiography and tomography might only reveal signs of intestinal obstruction, rarely determining the etiology.

The treatment is surgical, and the resection of the affected portion must be carried out, followed by primary anastomosis and correction of the hernia sac, in order to avoid future complications.

About the ligament of Treitz and its anomalous insertion observed in the intraoperative, no reports in literature were found. The Austrian doctor Wenzel Treitz initially described the duodenum suspensory ligament in 1853, which has been denominated as ligament of Treitz since(2). Two structures which constitute this ligament were described: a superior one, denominated as Hilfsmuskel, which emerges from the esophageal hiatus of the diaphragm, and an inferior one, that constitutes the duodenum suspensory muscle and emerges from it(2). In the above-described case, the inferior portion of the ligament of Treitz was located to the right side of the mesenteric arteries, without clinical repercussion.

\section{Conclusion}

Although the Meckel's diverticulum is a fairly 
common condition, Littré hernia is considered to be a rare surgical disorder, whose diagnosis is usually given in the intraoperative, and the treatment, in most cases, is surgical, by the resection of the affected segment. Regarding the anomalous position of the ligament of Treitz without clinical repercussion, the medical literature lacks data to draw conclusions.

\section{References}

1. Fernandez PM, Lucio LAG, Dias JLF, Pollachi F. Hérnia de Littré: relato de caso e revisão de literatura. Arq méd ABC. 2003;28(1):25-7.

2. Kim SK, Cho CD, Wojtowycz AR. The ligament of Treitz (the suspensory ligament of the duodenum): anatomic and radiographic correlation. Abdom Imaging. 2008;33(4):3957.https://doi.org/10.1007/s00261-007-9284-3

3. Lima Neto EV, Goldenberg A, Matos D. Hérnia de Littré. Rev Col Bras Cir. 2004;31(1):73-4 https://doi.org/10.1590/s0100-69912004000100015

4. Schizas D, Katsaros I, Tsapralis D, Moris D, Michalinos A, Tsilimigras DI, et al. Littre's hernia: a systematic review of the literature. Hernia. 2019;23(1):12530.https://doi.org/10.1007/s10029-018-1867-0

5. Skandalakis PN, Zoras O, Skandalakis JE, Mirilas P. Littre hernia: surgical anatomy, embryology, and technique of repair. Am Surg. 2006;72(3):238-43 https://doi.org/10.1177/000313480607200309

6. Souza HS, Felicio AC, Berthier G. Hérnia de Littré causando obstrução intestinal. Rev Col Bras Cir. 2009;36(2):183-4. https://doi.org/10.1590/s0100-69912009000200019 